Florida International University FIU Digital Commons

$11-21-1997$

\title{
Computer anxiety and nursing informatics needs of graduate nursing students
}

Margot Elizabeth Clark

Florida International University

DOI: $10.25148 /$ etd.FI14060842

Follow this and additional works at: https://digitalcommons.fiu.edu/etd

Part of the Nursing Commons

\section{Recommended Citation}

Clark, Margot Elizabeth, "Computer anxiety and nursing informatics needs of graduate nursing students" (1997). FIU Electronic Theses and Dissertations. 2374.

https://digitalcommons.fiu.edu/etd/2374

This work is brought to you for free and open access by the University Graduate School at FIU Digital Commons. It has been accepted for inclusion in FIU Electronic Theses and Dissertations by an authorized administrator of FIU Digital Commons. For more information, please contact dcc@fiu.edu. 


\section{FLORIDA INTERNATIONAL UNIVERSITY \\ Miami, Florida}

\section{COMPUTER ANXIETY AND NURSING INFORMATICS NEEDS OF GRADUATE NURSING STUDENTS}

A thesis submitted in partial satisfaction of the requirements for the degree of

MASTER OF SCIENCE

IN

NURSING

By

Margot Elizabeth Clark 
To: Dean DeLois P. Weekes

College of Health Sciences

This thesis, written by Margot Elizabeth Clark, and entitled: Computer Anxiety and Nursing Informatics Needs of Graduate Nursing Students, having been approved in respect to style and intellectual content is referred to you for your judgement.

We have read this thesis and recommend that it be approved.

\author{
Gregory Hopkins
}

Douglas Coffin

Martha Velasco Whetsell, Major Professor

Date of Defense: $11 / 21 / 97$

The thesis of Margot Elizabeth Clark is approved.

DeLois P. Weekes

Dean College of Health Sciences

Dr. Richard L. Campbell

Dean of Graduate Studies

Florida International University, 1997 


\section{ACKNOWLEDGMENTS}

Special thanks to Dr. Martha Velasco-Whetsell as my committee chairperson and for her classes in the research process. She has a true love for nursing research.

Special thanks to Dr. Douglas Coffin for classes in nursing informatics and one-to-one support to resolve my own computer anxiety.

I wish to thank Dr. Hopkins for his continued support throughout my graduate studies.

Thanks to my husband Bill for his undying support. 


\title{
ASTRACT OF THE THESIS \\ COMPUTER ANXIETY AND NURSING INFORMATICS NEEDS \\ OF \\ GRADUATE NURSING STUDENTS
}

\author{
By \\ Margot Elizabeth Clark \\ Florida International University, 1997 \\ Miami, Florida \\ Professor Martha Velasco-Whetsell, \\ Major Professor
}

The impact of technology in today's society affects every aspect of life. This study focused on exploring the extent of computer anxiety among graduate nursing students using the Oetting's computer anxiety scale. Computer and information seeking skills required for both education and advanced nursing practice were also assessed using a survey by Jacobs and dela Cruz. Special emphasis was placed on retrieval of information from large data-bases. The conceptual framework was based on Roy's Adaptation Model.

The sample consisted of 28 students enrolled in a nursing informatics class in a south Florida university. Frequency distribution, and t-tests were used to analyze the data. The results indicate that graduate nursing students have a mild computer anxiety. Perceived informatics needs included Internet use, electronic mail, compiling research, and thesis construction. Results of the study may be used to identify future curriculum content for nursing informatics classes. 


\section{TABLE OF CONTENTS}

CHAPTER

PAGE

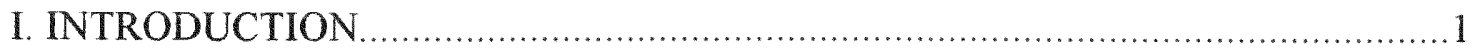

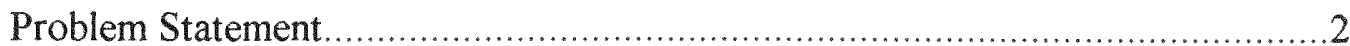

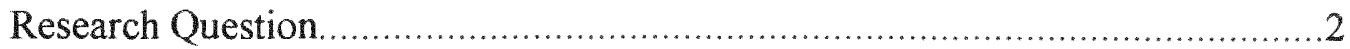

Research Purpose

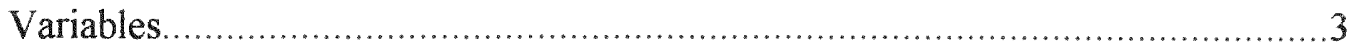

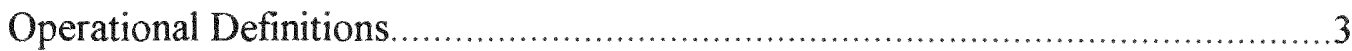

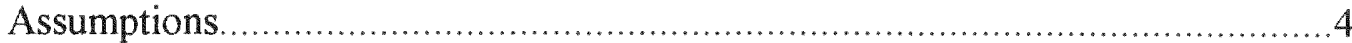

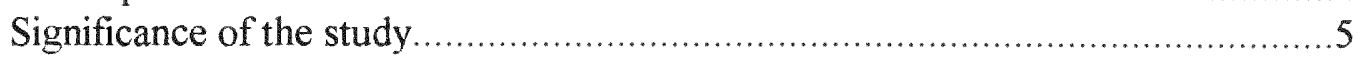

II. REVIEW OF THE LITERATURE

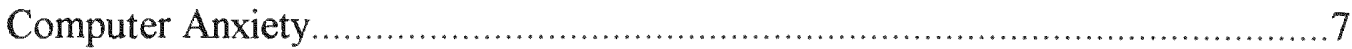

Computer Trends in Nursing .................................................................. 11

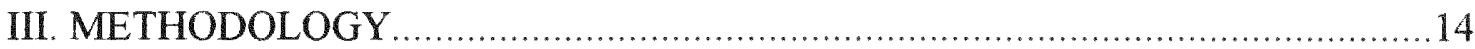

Research Design/Sample............................................................... 14

Data Collection Instruments.................................................................. 14

Method of Data Collection........................................................................... 15

IV. RESULTS

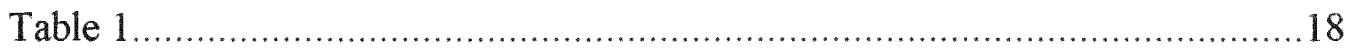



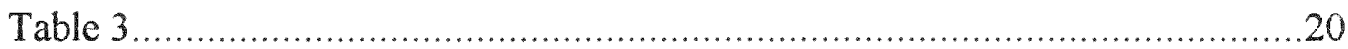

Computer Applications for Clinical Practice................................................22

Computer Applications for Nursing Education............................................24

Computer Applications for Nursing Research ........................................25

Computer Applications for Nursing Administration....................................26

V. DISCUSSION

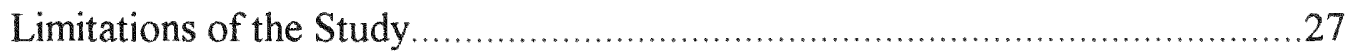

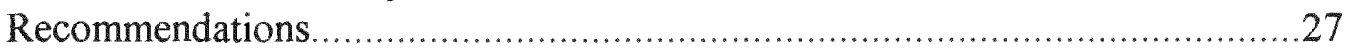

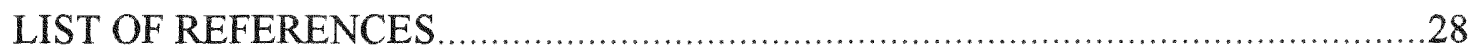

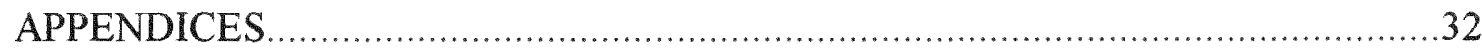




\section{CHAPTER I}

\section{INTRODUCTION}

Technological advances are affecting every aspect of society. Computers are used in every facet of daily life. Computer illiteracy in today's workplace is as much of a disadvantage as not being able to read and write. Since computers were introduced in health care more than three decades ago, many studies have been published about computers and nursing (Axford \& Carter, 1996). Nurses returning to school to pursue an advanced degree meet the cultural shock of technology. Past undergraduate education of many students did not include computer courses.

Word processing skills are necessary for survival, however nursing informatics needs of graduate students are far greater than word processing. Special library sessions are often available for those students who are surprised to find there are no longer card catalogues to index library books. Literature searches are done via compact disc files which compile abstracts used to locate nursing research.

The Internet provides a wealth of information and access to prestigious university resources. Communication via electronic mail (E-mail) allows direct communication with the authors of research, professors, and other experts or professional colleagues. Up to the minute data on infectious disease statistics, treatment protocols, or medications are also available on the Internet. Graduate students are often called upon to develop and present classroom lectures. Computer programs can generate graphics and slides for enhanced presentations. Computer assisted instruction can be used as teaching aids in 
clinical areas or for staff development.

Graduate students who lack previous computer knowledge are at a disadvantage. The challenge of graduate school along with the impact of this new technology may cause apprehension and anxiety. The need for classes in nursing informatics far outweighs the availability of these computer classes in most graduate institutions.

\section{Problem Statement}

Computer courses have not been included in traditional nursing education curriculums. Graduate students need education in many areas of computer applications, and lack of these skills causes tension and anxiety. Advanced practice nurses are leaders and should be proficient in the use of computers in order to adapt to technological advances which may be required of their positions in the workplace.

\section{Research question}

To what degree do graduate nursing students experience computer anxiety? What are the perceived nursing informatics needs of graduate nursing students? What perceived content should be included in nursing informatics classes to facilitate better computer skills conducting research, writing a thesis, and best prepare the graduates for their new roles as nurse practitioners?

\section{Research purpose}

The purpose of this study is to measure the levels of computer anxiety in graduate nursing students and survey computer information needs for both education and advanced practice nursing. 


\section{Variables}

The dependent variable is computer anxiety, which will be measured by administering a computer anxiety test, the Compas, (E.R. Oetting 1983). The independent variables: age, years of nursing experience, number of semesters completed in the graduate program, type of formal computer education, areas of specialization, and self reported computer skills will be measured using a Survey of Masters Students Concerning Computer/Informatics Skills (dela Cruz,\& Jacobs, 1993).

\section{Operational Definitions}

Graduate nurse practitioner students: Refers to those students who are enrolled in a Master of Science in Nursing and Nurse Practitioner program. Various educational backgrounds include: licenced practical nursing, diploma nursing, and associate degree nursing, all baccalaureate prepared, and some mastered prepared nurses becoming nurse practitioners.

Nursing Informatics: The American Nurses Association Standards of Practice, (1995) has defined nursing informatics (NI) as the "specialty that integrates nursing science, computer science, and information science in identifying, collecting, processing and managing data and information to support nursing practice, administration, education, research, and the expansion of nursing knowledge"( p.1). .

Computer Anxiety refers to an individuals unpleasant emotional state, characterized by feelings of tension, apprehension, nervousness, and worry in response to computers. Levels of computer anxiety as scored on the Compas Computer Anxiety Scale (Oetting 
1983). The overall computer anxiety scale ranges from (40 to 200). Individual scores are calculated using a scoring key. The following labels are based on scores falling within the ranges as indicated by Oetting: relaxed and confident ( 40 to 79 ), comfort zone ( 80 to 105 ), mild anxiety (106 to 120 ), anxious and tense (121 to 140 ), and very anxious (141 to 200).

\section{Assumptions}

1) Computer anxiety results from lack of instruction and/or experience.

2)The degree to which one suffers computer anxiety can be measured by a self-report questionnaire.

3)Students gain computer experience throughout the course of the graduate program because the curriculum demands research, papers, and presentations.

Null Hypothesis: Graduate nursing students have no computer anxiety.

Hypothesis: There is an inverse relationship between computer skills and levels of computer anxiety.

\section{Significance of the study}

Undergraduate nursing curriculums could be improved by requiring computer education classes. More graduate nursing programs may incorporate nursing informatics classes that are tailored to meet the computer learning needs of advanced practice nurses. Enhanced computer skills will enable the students to conduct research, make more creative presentations, compile and analyze statistics, and prepare a thesis. This knowledge base will enable them to tackle more difficult computer problems with 
confidence instead of anxiety. These practitioners will also be better prepared to meet the demands of technology as they assume their new roles in the community.

\section{Theoretical Framework}

Sister Callista Roy's Adaptation Model will be used as a conceptual framework for this study. Roy views human beings as biopsychosocial systems who cope with environmental changes through the process of adaptation. Within the human being there are four subsystems: physiologic needs, self concept, role function, and interdependence. (Polit \& Hungler, 1993). The focus of this study involves the self concept. Individuals are holistic beings that are in constant interaction with their environments, exchanging information, matter and energy. Characteristics of Roy's system include inputs, outputs, controls and feedback (George, 1995).

Inputs are identified by Roy as focal, contextual, and residual stimuli. For example the graduate student who lacks computer skills enrolls in a computer class to gain such skills. The computer class would be the focal stimuli. Contextual stimuli is made up of all other surrounding stimuli such as: the graduate student's family, work environment, the other aspects of university environment, and the student's general state of health. Residual stimuli includes the students past experience, knowledge, strengths, beliefs, and limitations. Enrolling in a computer education class is an adaptation response to the need for computer education. The adaptation level of an individual is in constant change, and can vary at any particular point in time. Adaptation problems occur when there is an inadequate response to stimuli. (Marriner-Tomey, 1994). 
Outputs are the responses a person makes to focal stimuli, and become feedback to the person and to the environment. Responses can be either adaptive or ineffective. Learning would be an adaptive response to the focal stimuli or the computer class. An ineffective response may include avoidance behaviors such as having someone type papers, or having a librarian conduct literature searches. Adaptive responses promote individual integrity and lead to the growth of the individual, while ineffective responses lead to maladaptive behaviors and responses.(George, 1995).

Roy (1991) cites "Indications of adaptive difficulty include signs of pronounced regulator activities signs such as increase in heart rate or blood pressure, tension, excitement, and loss of appetite." "Signs of cognator ineffectiveness include: faulty perception or information processing, ineffective learning, poor judgement and inappropriate affect" (Roy, 1991. p.32). The symptoms described as "regulator activities" such as increased heart rate, increased blood pressure, tension, and loss of appetite are also symptoms of anxiety, or computer anxiety if evoked when attempting to use the computer. "Excessive stimuli may not be accommodated within the adaptive zone and the response will be negative or maladaptive" (McIntosh, 1996, p. 983). 


\section{CHAPTER II}

\section{REVIEW OF THE LITERATURE}

\section{Computer Anxiety}

Anxiety refers to an individuals emotional state of distress, or uneasiness of mind, caused by anticipating danger or misfortune. State and trait anxiety are two types of anxiety described by Spielberger (1966). Trait anxiety is an individuals characteristic way of reacting to arousal. Some people report feelings of anxiety on a daily basis and have a predisposition to anxiety as part of their personality. Trait anxiety is not related to situations, but a pervasive feeling. People who experience trait anxiety often feel they have no control over the things that are happening in their lives.

State anxiety is increased anxiety provoked by a certain situation or experience, whether real or imagined. It may be a learned response to a previous experience or it may be fear of a new situation. Common symptoms of anxiety are: change in appetite or weight, change in sleeping habits, fatigue, irritability, trouble concentrating, and trouble learning.

Some anxiety is normal. In fact, a little anxiety is a common way of coping with life's routine challenges. But for some people anxiety is so prominent or excessive that it interferes with concentration, work, relationships, or physical well-being. Everyone feels anxious sometimes and low levels of anxiety actually can stimulate learning and productive work. Coping skills are needed to effectively deal with anxiety.

Anxiety can inhibit learning in a wide range of functions such as attention, memory, 
and problem solving. Learning anxiety is closely related to arousal, attention and motivation. In an educational setting, anxiety is triggered by a situation that requires a decision or judgment such as a test or exam. (Sieber, Oneil, \&Tobias, 1977).

Computer anxiety is a third type of anxiety which is known as a concept specific anxiety. Examples of concept anxiety would be: feelings of anxiety when exposed to cats, speaking anxiety, or anxiety about flying. Computer anxiety is a feeling of apprehension when attempting to use or learning how to use a computer. (Oetting, 1983). The absence of computer anxiety does not necessarily indicate the person is computer competent, but may reflect lack of interest or boredom, and it is hard to overcome (Fajou, 1997).

"Technostress" or computer related stress was studied by Kupersmith (1992) in relation to reference librarians. Technostress was described as a modern disease of adaptation caused by an inability to cope with the new computer technologies in a healthy manner. Technostress is described most commonly in those who feel pressured by their employers, peers, or general culture to accept and use computers. Coping mechanisms to deal with technostress may vary with the individual form initiating an instruction program to hiding under one's desk. (Kupersmith, 1992).

Computer anxiety is a complex issue. Teachers need to be aware of the ways in which to reduce computer anxiety. Fear is a strong emotion that many people feel in regards to computers, the fear of the unknown. This anxiety and fear may possibly be overcome through gaining experience with computers. Students will need to have computer skills regardless of their field of work, and those students with computer skills will be 
advantaged when it comes time for employment. Students suffering from computer anxiety will be extremely disadvantaged (Fajou, 1997).

Jayasuriya and Caputi (1996) conducted a study involving 71 first year nursing students and 99 hospital employed nurses, in order to measure attitudes toward computers. An instrument, Nurses' Computer Attitude Inventory (NCATT) was developed to test the reliability and the validity of the instrument. It was determined that the NCATT is a practical instrument that is useful to assess nurses attitudes before computer implementation and training. The Cronbach alpha coefficients ranged between 0.72 and 0.90 . The study investigated three factors (1) computers and patient care, (2)computer anxiety and (3) patient confidentiality and computers. The study suggested that negative attitudes and computer anxiety are the key factors in predicting resistence to the introduction of computers in the work place. This instrument was determined to be a valid, practical measurement to assess nurses attitudes before computer implementation and training. Prior strategies could be developed to reduce the resistence to change. The study also revealed nurses have concerns regarding patient confidentiality and computers in the work place.

McBride and Nagle (1996) studied factors that influence the attitudes of registered nurses and student nurses toward computers. Stronge and Brodt's Nurses Attitudes Toward Computerization questionnaire (NATC) was the instrument of choice. A large convenience sample consisted of 394 registered nurses employed in a large metropolitan hospital and 299 baccalaureate student nurses. The basis of the study was to investigate if 
nurses attitudes towards computers were an antecedent to behavior. Strong and Brodt's NATC self reported was designed to measure nurses positive attitudes towards computers and has been used in a variety of studies but had only limited psychometric testing (McBride \& Nagle, 1996). The initial study by Strong and Brodt (1986) found that level of education, years of experience and type of nursing unit were associated with a positive attitude towards computers. However psychometric testing revealed no consistent relationships between variables of level of education, years of nursing experience or type of nursing unit, and nurses attitudes as measured by the NATC instrument. Therefore recommendations were made for further understanding of nurses attitudes toward computers (McBride \& Nagle, 1996).

Speier, Morris, and Briggs (1996) conducted a large study involving 959 students enrolled in an introductory computer class at a large Midwestern university. Subjects were given a questionnaire the first day of class before students had any class exposure to computers. A second questionnaire was used to collect data after 15 weeks of training. The training included one lecture per week, and two days of hands on training in the computer laboratory. Factor analysis was performed on the items used in the questionnaire, and psychometric properties of the instrument were acceptable. Correlation coefficients of attitudes and performance were significant at the .05 level. Additionally t-tests were run between initial and final attitudes on performance. Those subjects who perceived computers to be useful and easier to use, had higher levels of skill performance. 
The negative correlation between anxiety and performance actually increased over fifteen weeks of training. This finding was highly significant as indicated by the t-test results. The data suggests that subjects who exhibit computer anxiety prior to the class are likely to continue to be anxious about computer use after going through training. Training and computer use may reinforce anxiety in students who indicated high initial anxiety and ultimately poor performance. Findings from this study suggest it might be useful to identify those students who have high computer anxiety and provide one-one-one instruction or mentoring. These measures may help to overcome the feelings of computer anxiety.

\section{Computer Trends in Nursing Practice}

According to Manning \& McConnell (1997), nursing information systems are computer systems that enable nurses to collect, manipulate, store, retrieve, display, and communicate data to administer nursing services and resources, manage nursing practice, improve patient care, and advance nursing knowledge. Hospital corporations are becoming more computer oriented and some hospitals have become totally paperless.

Critical thinking is becoming more important for nurses in today's health care system. The nurse must be able to utilize a broad base of knowledge, coordinate patient care, utilize resources, and evaluate outcomes in a constantly changing environment. Jacobs, Ott, Sullivan, Ulrich \& Short (1997) are nursing faculties in a Midwestern university who developed a tool to define and measure critical thinking. "The following definition of critical thinking was written: Critical thinking is the repeated examination of problems, 
questions, issues, and situations by comparing, simplifying, synthesizing information in an analytical, deliberative, evaluative decisive way" (Jacobs, et al. 1997, p. 20). Nurse educators must teach in such a way as to encourage the development of critical thinking skills. Besides teaching just information the nurse educator must expect the students to apply the information in the form of problem- solving. Jacobs et al. (1997) examined the use of case studies, care plans, and course papers to determine evidence of critical thinking.

The Internet is also known as the information super highway began in 1969 as a research project for the United States Military in order to decentralize computer connections in the event of computer sabotage. Universities became involved with further development and not until 1990 could the public get involved.

Owsten (1997) explores the effectiveness of teaching and learning on the World Wide Web as compared to the physical boundaries of a classroom and class schedules. Access to higher education is becoming available at some universities providing courses over the Internet. City University in Bellvue, Washington recently established Education Resource and Online Academic Degree Systems (EDROADS). At the present, it provides an on-line Masters in Business Administration, and an on-line Bachelor of Science in Computer Systems. Students from around the world apply to the university, register for courses, and complete course work electronically (Owsten, 1997). Birbeck College of the University of London, England, and the University of Massachusetts Dartmouth Division of Continuing Education (CyberEd) offer distance learning programs (Owsten, 
1997). While these programs are not accredited, they are blazing the trail of a "virtual university" and what may become a common way of study in the near future.

The University of Kansas School of Nursing offers five masters degree core courses over the Internet to nearby rural areas. Nurse forum is an international on-line communication network developed by the American Nurses Association. This site includes data libraries, conference rooms, and message areas. Message areas allow a user to join in conversations that are in progress or to start a new one.

Senior nursing students from Case Western University Frances Payne Bolton School of Nursing in Cleveland designed and built NurseWeb. This site provides access to nursing and patient care resources including assessment and intervention procedures for suspected child abuse, cancer guidelines and health education materials. A growing number Journals containing the most recent clinical news and legislation can be accessed. Continuing education is available on-line. Consultations with experts or peers are available by electronic mail (email) for puzzling clinical cases. Some rural areas have access to large medical centers through video conferencing. 


\section{CHAPTER III}

\section{METHODOLOGY}

\section{Research Design/Sample.}

A convenience sample was comprised of 28 students enrolled in nursing informatics classes. This course is available as an elective while pursing a Masters Degree in Nursing and Nurse Practitioner degree. The students surveyed may include students who have recently enrolled in the program, some at midpoint, as well as some who are nearing completion of the program. Statistical Products and Services Solutions Inc. (SPSS), a computer program utilized to analyze the data.

\section{Data Collection Instruments}

The computer anxiety scale, COMPAS, was developed by Dr.E.R. Oetting (1983) to determine computer anxiety levels. This scale is reliable with a Chronbach alpha coefficient of 96 percent. There is considerable evidence that it is both a reliable and valid as a measure of computer anxiety. Each of 48 questions is followed by a pair of adjectives separated by a five point Likert- scale. Results can be interpreted using the raw score which is computed using a scoring key. Responses to the negatively worded statements are reverse scored to make all responses consistent for analysis. The overall computer anxiety scale ranges from (40 to 200 ). A score (40 to 79 ) indicates very relaxed and confident, ( 80 to 105$)$ indicates a comfort zone, (106 to 120$)$ mild anxiety, (121 to 140$)$ anxious and tense, and (141 to 200$)$ very anxious. 
The second tool is a "Survey of Masters Students Concerning Computer/Informatics Skills" (dela Cruz, \& Jacobs 1993). "A content validity index of .92 was derived using Popham's method of average congruency" (1993, p. 337) . "The test reliability was .86, which was the mean of the agreement scores on each of the questionnaire items when the responses of the test and retest administrations were compared"(1993, p. 338).

Additional demographic information was obtained including previous computer training, and areas of desired skill advancement. Space was provided for students to make additional comments and to relate stressful computer experiences.

\section{Method of Data Collection}

This study design is a comparative descriptive study using a paper and pencil questionnaire. Permission to conduct the study was obtained from the University Institutional Review Board. Prior arrangements and permission to conduct the study were obtained from the professor teaching the classes. The investigator arranged for a ten minute period of time at the end of a regularly scheduled class to explain the purpose of the study and request participation by the students. No incentives were given and participation was voluntary.

The questionnaires, packaged in brown envelopes were distributed at the end of a class. The instructions were to return the sealed brown envelopes containing the completed questionnaires at the next regularly scheduled class. A clearly labeled box was provided and the students were to deposit the completed questionnaires in the box. The investigator collected the completed questionnaires at the end of the next class period. 
The two questionnaires would have matching numbers to correlate data from the Compas and the Computer informatics survey.

The sampling included students at all levels of the graduate program for advanced nurse practitioners. A cover letter was included explaining the purpose of the voluntary study, and completion of the questionnaire indicated consent. Confidentiality and anonymity were maintained in order to protect the rights of human subjects. 


\section{CHAPTER IV}

\section{RESULTS AND DISCUSSION}

The Oetting Computer Anxiety Scale (Oetting, 1983) may produce score that range from (40 to 200). Interpretation of the scores is as follows: Relaxed and confident (40 to 79), Comfort zone ( 80 to 105 ), Mild anxiety (106 to 120$)$, Anxious and tense (121 to 140 ), and Very anxious (141 to 200 ). The 28 graduate nurse practitioner students enrolled in a nursing informatics course had a range of scores from 51 to 172 with a mean anxiety score of 111.6 indicating "mild" computer anxiety. However this result can be misleading. Fifty percent of the students surveyed were "anxious/tense" to "extremely anxious". Twenty-five percent of the students scored in the "relaxed" range. Eighteen percent of the students scored in the "comfort" range, and only seven percent of the graduate students scored in the "mild" range.

The Survey of Masters Students Concerning Computer Informatics Skills (dela Cruz \& Jacobs, 1993) revealed an educational need exists among graduate nursing students in most areas of computer applications. Of the surveyed students $71 \%$ work in clinical positions, $11 \%$ in administrative positions, and $5 \%$ in education positions. Of the respondents $93 \%$ were female, ages ranged from 25 years to 47 years with a mean age of 36 years, $75 \%$ have 6 or more years of nursing experience, $68 \%$ report having a computer at home and work. 
Table 1. Graduate Nursing Students: Demographic and Experiential Characteristics $(\mathrm{n}=28)$

Characteristics of Respondents $N=$ Percent

\begin{tabular}{|l|c|c|}
\hline Work Specialty & & \\
Clinical & 20 & $71 \%$ \\
Education & 5 & $18 \%$ \\
Administration & 3 & $11 \%$ \\
Years Nursing Experience & & \\
\hline $1-2$ years & 2 & $7 \%$ \\
$3-5$ years & 5 & $18 \%$ \\
$6-10$ years & 9 & $32 \%$ \\
$11+$ years & 12 & $42 \%$ \\
Age Group & & \\
\hline $25-29$ years of age & 6 & $21 \%$ \\
$30-39$ years of age & 13 & $47 \%$ \\
$40-49$ years of age & 9 & $32 \%$ \\
Semester Hours Completed & & \\
3-9 & 9 & $32 \%$ \\
$10-18$ & 10 & $35 \%$ \\
$19-27$ & 3 & $11 \%$ \\
$28-36$ & 5 & $18 \%$ \\
$37+$ & 1 & $4 \%$ \\
Access to Computer & & \\
Home & 7 & $25 \%$ \\
Work & 2 & $7 \%$ \\
Both home and work & 19 & $68 \%$ \\
Gender & & \\
Females & 26 & $93 \%$ \\
Males & 2 & $7 \%$ \\
& & \\
\hline
\end{tabular}


While the majority of students have some skills in word processing (beginning skills $50 \%$ ), (advanced skills $29 \%$ ), and (expert skills $7 \%$ ), it is very concerning that $14 \%$ of the student have no knowledge of word processing. Most students lack skills in the use of spread sheets $(61 \%)$, learning modules $(50 \%)$, decision analysis $(86 \%)$, and statistical analysis (79\%).

It is understandable that the majority of the graduate students lack computer skills related to patient accounts such as spread sheets $(61 \%)$ and billing $(64 \%)$. However nurse practitioners may become involved in these types of functions as they become involved in joint or independent practices.

Ability to access patient information is a basic skill advanced nurse practitioners must have. Since the majority of students $(71 \%)$ work in clinical areas, of great concern is the percentage of these students lacking computer skills in the following areas: patient monitoring $28 \%$, accessing patient information $14 \%$, computer medicine calculations $43 \%$, computer care planning $47 \%$, and computer documenting $43 \%$.

Graduate students reported their literature searching abilities as follows: $42 \%$ do literature searches by themselves, $32 \%$ do the search with librarian help, $21 \%$ ask others to do the search, and 4 percent have never done a literature search. The students surveyed have completed an average of 14.87 semester hours which is one third of the 42 required semester hours to complete the program. 
Table 2. Graduate Nursing Students: Self-reported Skill in Computer Use $\mathrm{N}=$ Frequency and Percentage of Respondents

\begin{tabular}{|l|l|l|l|l|l|}
\hline Skills Application & & $\begin{array}{l}\text { Beginning } \\
\text { Skill }\end{array}$ & $\begin{array}{l}\text { Advanced } \\
\text { Skill }\end{array}$ & $\begin{array}{l}\text { Some } \\
\text { Skill }\end{array}$ & $\begin{array}{l}\text { No } \\
\text { Skill }\end{array}$ \\
\hline Word processing & 28 & $14(50 \%)$ & $10(36 \%)$ & $24(86 \%)$ & $4(14 \%)$ \\
\hline Spreadsheets & 28 & $9(32 \%)$ & $2(7 \%)$ & $11(39 \%)$ & $17(61 \%)$ \\
\hline Learning modules & 28 & $9(32 \%)$ & $5(18 \%)$ & $14(50 \%)$ & $14(50 \%)$ \\
\hline Decision Analysis & 28 & $2(7 \%)$ & $2(7 \%)$ & $4(14 \%)$ & $24(86 \%)$ \\
\hline Statistical Analysis & 28 & $6(21 \%)$ & $0(0 \%)$ & $6(21 \%)$ & $22(79 \%)$ \\
\hline $\begin{array}{l}\text { Practice } \\
\text { Applications }\end{array}$ & & & & & \\
\hline Patient monitoring & 28 & $10(36 \%)$ & $10(36 \%)$ & $20(72 \%)$ & $8(28 \%)$ \\
\hline Patient information & 28 & $8(28 \%)$ & $16(57 \%)$ & $24(86 \%)$ & $4(14 \%)$ \\
\hline Medicine calculation & 28 & $7(25 \%)$ & $9(32 \%)$ & $16(57 \%)$ & $12(43 \%)$ \\
\hline Care planning & 28 & $6(21 \%)$ & $9(32 \%)$ & $15(53 \%)$ & $13(47 \%)$ \\
\hline Documenting & 28 & $5(18 \%)$ & $11(39 \%)$ & $16(57 \%)$ & $12(43 \%)$ \\
\hline
\end{tabular}

The most common method of describing the relationship between two measures is through correlation procedures. To what extent are two variables related to each other? This question can be answered by the calculation of the correlation coefficient. A perfect relationship is (1.0) or $(-1.0)$ for inverse relationships. In the study of human beings a relationship is never perfect, therefore a correlation coefficient of $(.5$ to .6$)$ or $(-.5$ to -.6$)$ is considered of significance (Polit \& Hungler, 1993).

The Statistical Products and Service Solutions Inc. (SPSS) program was used to analyze the data. The correlation procedure utilizes the Pearson product-moment correlations which summarize the relationship between two variables. The value of the 
correlation coefficient ranges from $(-1)$ to $(+1)$. The strength of the relationship between two variables is determined by the magnitude of the correlation coefficient; the sign of the correlation coefficient $(+$ or - ) informs us about the direction of the relationship between two variables.

The $t$-test procedure is used to test for a statistically significant difference in means between two groups. The t-test computes a t-value which is a standardized score that is calculated by dividing the difference in means between the two groups by its standard error (i.e., the standard deviation of the mean differences).

A t-test conducted for the paired samples: (computer anxiety) and (total semester hours completed) indicates a strong positive correlation (.102). This indicates as the anxiety level goes up so do the number of semester hours completed go up. This may be due to additional pressures the students experience near the completion of the graduate program, including thesis or master's papers. If the sample size were larger, more significance could be attached to the findings.

A t-test was also conducted on the paired samples: (computer anxiety scores) and the (self-reported skill scores). The relationship shows some significance with an inverse or negative correlation (-.321). As the number of reported computer skills goes up the anxiety score goes down. This result lends support to the hypothesis that computer experience will decrease computer anxiety. The following tables record the results of the t-tests conducted with SPSS. 
Table 3. Results of t-tests for paired samples.

Variables \# pairs Corr 2-tail sig Mean SD SE of mean

\begin{tabular}{|lrrrrrr|}
\hline ANXIETY SCORE & \multicolumn{7}{c}{111.6786} & 34.574 & 6.534 \\
\hline & 28 & $(.102)$ & $(.606)$ & & & \\
\hline TOTAL SEMESTERS COMPLETED & & 14.8571 & 11.359 & 2.147 \\
\hline
\end{tabular}

\begin{tabular}{|lccccccc|} 
Variables & \# of pairs & Corr & 2-tail sig & Mean & SD & SE of mean \\
\hline ANXIETY SCORE & & & & 111.6786 & 34.574 & 6.534 \\
\hline & 28 & $(-.321)$ & $(.096)$ & & & \\
\hline SKILLS & SCORE & & & & 10.8214 & 6.600 & 1.247 \\
\hline
\end{tabular}

Corr $=$ Correlation co-efficient

$\mathrm{SD}=$ Standard deviation

$\mathrm{SE}=$ Standard error of the mean

A number of respondents would like to advance their computer skills in the

following areas: Thesis construction (25), Statistical analysis (20), Internet (24), E-mail

(17), Computer Fax (14), Interactive learning (12), Downloading software (24),

Compressing files (21), Creative presentations (21).

The following items were reported as stressful computer experiences. The number indicates how many respondents reported the same problems: Printer problems (4), Electrical failure (3), virus (1), slow modem (3), losing data (5), can't connect to the Internet (4). 


\section{Computer Applications for Clinical Practice}

The role of advanced practice nurses (APN) is rapidly developing as are changes in the health care delivery system. Large corporations are more efficiently managing hospitals. Health care maintenance organizations (HMO'S) are financing much of health care today. The consumer is playing a more active role in their own health care. All these factors combine to present an environment that emphasizes health promotion, disease prevention, and health care delivery at a reasonable cost. Delaney (1996) outlines the need for APN's to have computer informatics skills in order to access information systems to meet the goals of building healthier populations.

Clinical information systems have been developed to aid in diagnostic decision making. These expert computer systems are designed to mimic the human expert. According to Meyer et al. (1996) these computer programs must be closely scrutinized. Advanced practice nurses must be actively involved in the design, development and clinical trial evaluations of all nursing expert systems. Significant limitations have been identified in the abilities of the expert system to mimic the consultation process of the APN. Masters prepared nurse practitioners will be involved in setting standards of care in the clinical setting. Clinicians will need to be knowledgeable concerning clinical information systems. Large computerized data base management systems are used access a range of patient data to plan, implement and evaluate care (Axford, \& Carter, 1996). 


\section{Computer Applications for Nursing Education}

Lewis \& Watson (1997) conducted a study to determine faculty concerns about the use of computer technology. The study's population consisted of the graduate and undergraduate nursing faculty at a university school of nursing. A standardized questionnaire (Stages of Concern) was designed to measure concern about change. This an author developed survey included questions concerning computer skills. Of the 57 faculty, 25 returned the questionnaires, and 28 attended a monthly workshop. This workshop was given over a period of eight months, each session lasting about 2 hours. Content included basic computer literacy, word processing, presentation development, computer based instructional materials, data base management, and spread sheet applications. A pre and post test was given. Results indicated that a series of faculty development workshops seemed to reduce technology anxiety and to increase the faculty's comfort level with technology. One area of concern was the majority of faculty members who attended the workshops did not have computers available in their offices.

Nurse educators themselves must be comfortable enough with computer technology to be able to incorporate computer technology in their classrooms. Internet publishing, and the development of on-line education courses will be in the job description of the future nurse educators. A few instructors now communicate with their students via E-mail. Nursing educators are beginning to use instructional technology such as computer assisted instruction (CAI) in both graduate and undergraduate education.

Some futuristic nursing education scenarios are being developed. Virtual reality programs are being designed to allow simulation of actual patient encounters. A virtual 
reality experience may allow students to experience real life-like scenarios in the privacy of a computer laboratory. Unpleasant reactions by a nurse to a wound, a colostomy, or a burn, that may harm a sensitive patient who is watching the care giver, may be avoided.

\section{Computer Applications for Nursing Research}

Nurse researchers would benefit from having access to research that is in progress as well as establishing contact with other researchers interested in similar areas of study. Although thousands of nurses conduct research no library in the past was devoted to serving as a focal point for nursing research. Work toward the development of an international nursing library was begun during the 1987 Sigma Theta Tau international convention (Hudgings, 1992), and was named the Virginia Henderson International Nursing Library.

This Virginia Henderson International Library is available today on the Internet. This site provides innovative data, information, and knowledge about nursing research through two services, 1)a registry for nursing research, and 2) an on-line Journal of Knowledge Synthesis for Nursing. This site is maintained by Sigma Theta Tau International, the International Honor Society of Nursing. Data contributed by nurse researchers as well as abstracts from national nursing research conferences are available to subscribers. Also new research projects underway, and information about the researchers and the the findings of their research are available. 


\section{Computer Applications for Nursing Administration}

Automated staffing, utilization review, continuous quality improvement, workload monitoring, and discharge planning are some of the responsibilities of nursing administration. All of these labor intensive monitoring tasks can be efficiently managed using the computer. Confidentiality of patient information has been an issue slowing the progress of patient care documentation. Communication between different levels of management can be handled via E-mail. Up to the minute advisement concerning problems can facilitate speedy management of problems before they escalate Arnold (1996) conducted a study among 497 nurse educators, nurse mangers, and informatics nurses in a northeastern metropolitan area in order to determine the informatics needs of professional nurses. Subjects were asked about their current knowledge and their desired knowledge in 23 areas of computer applications. Word processing, e-mail, databases, and spreadsheets were the top computer applications used by this population. The subjects were interested in further educational preparation concerning: graphic presentation of data, decision support systems, electronic communications, integration of computers in nursing education, computer assisted instruction, and expert knowledge acquisition. Post masters programs were recommended for this population since 71 percent of the respondents already possessed a higher degree. 


\section{Limitations of the Study}

Although this study was limited by the sample size, the survey underscored the need to incorporate nursing informatics into graduate and undergraduate nursing programs. It is difficult to conduct tests measuring computer skills in all aspects of nursing, so the convenience of using a self-report of skills was utilized. Computer anxiety may decrease as the younger population that have been exposed to computers since early childhood enter the workforce.

\section{Recommendations}

The investigator presents the following recommendations:

1. This study could be conducted utilizing a pre-test and a post test of computer anxiety to determine if a computer class serves to decrease computer anxiety.

2. An actual computer skill test instead of a self-report of skills may provide more accurate results.

3. A study measuring computer anxiety in students near completion of the graduate nursing studies could be given. Determine which students completed the course in nursing informatics, and make a comparison of the two groups concerning computer anxiety levels.

4. Identify those students with high levels of computer anxiety early in the informatics course, assign one-to-one assistance utilizing graduate students majoring in computer science, then conduct a post course computer anxiety test. 


\section{REFERENCES}

American Nurses Association (1995) Nursing Data Systems: The Emerging Framework.

Washington, DC: American Nurses Publishing.

American Nurses Association (1995) Standards of Practice for Nursing Informatics.

Washington, DC: American Nurses Publishing.

Arnold, J.M. (1996). Nursing informatics educational needs. Computers in Nursing 14

(6): 333-339.

Arnold. J.M., Pearson, G.A., (1993). Computer Applications in Nursing Education and

Practice. New York. National League for Nursing.

Axford, R.L., Carter, E.L. (1996). Impact of clinical information systems on nursing practice. Computers in Nursing 14 (3). 156-163.

Delaney, C. (1989). Nurse educators acceptance of the computers in baccalaureate nursing programs. Computers in Nursing 7 (3). 129-136.

Delaney, C., (1995). Use of nursing informatics in advanced practice roles for building healthier populations. Advanced Practice Nursing Quarterly 1 (4):48-53,

Evans, S., (1997). Computers and Medicine: The Pace System An Expert Consulting System for Nursing. New York. Springer.

Fajou, S. (1997). Computer Anxiety. Faculty of Education University of Sydney.

[On-Line], Available: http://www.edfac.usyd...ojects/comped/Fajou.html. 
George, J. B., (1994). Nursing Theories: The base for Professional Nursing Practice ( $4^{\text {th }}$ ed.). Norwalk, CT: Appleton \& Lange.

Grobe, S.J., Pluyter-Wenting, E. S., (1994). Nursing Informatics: An International

Overview For Nursing In A Technological Era. Amsterdam. Elsevier Science.

Hudgings, Carole, (1992). The Virginia Henderson International Nursing Library:

Improving Access to Nursing Research Databases. Computer Applications in

Nursing education and Practice. National League for Nursing: New York.

Jacobs, M., \& dela Cruz, F.A. (1993). The Informatics and Education Needs of

Graduate Nursing Students. Computer Applications in Nursing Education and

Practice. New York: National League for Nursing: New York.

Jacobs, P.M., Ott,B., Sullivan, B., Ulrich, Y., Short,L. (1997). An approach to defining and operationalizing critical thinking. Journal of Nursing Education 36 (1) $19-22$.

Jayasuria, R., Caputi, P. (1996), Computer attitude and computer anxiety. Computers in Nursing $14(6): 340-345$

Kupersmith, J. (1992) Technostress and the reference librarian. Reference Services Review, (7), 14-50.

Lewis, D.,Watson, J.E., (1997) Nursing faculty concerns regarding the adoption of computer technology. Computers in Nursing 15 (2). 71-76.

Manning, J., McConnell, E.A. (1997). Technology assessment : A framework for generating questions useful in evaluating nursing information systems. Computersin Nursing 15 (3): 33-38. 
Marriner-Tomey, A. (1994). Nursing Theorists and Their Works (3rd ed.). St. Louis: Mosby.

McIntosh, J. (1996). The Roy Adaptation Model: a consideration of it's properties as a conceptual framework for an intervention study. Journal of Advanced Nursing 24 (3): $981-987$.

McBride, S.H., Nagle, L.M. (1996). Attitudes toward computers a test of construct validity. Computers in Nursing 14 (3), 164-170.

Meyer, K.E., Sather-Levine, B., Laurent-Bopp, D., Gruenewald, D., Nichol, P., Kimmerle, M., (1996). The impact of clinical information systems on the future of advanced practice nursing. Advanced Practice Nursing Quarterly 2 (3), 58-64.

Oetting, E.R. (1983). Manual for Oetting's Computer Anxiety Scale (Compas). Tri-ethnic Center for Prevention Research. Colorado State University, Fort Collins, Co.

Owston, R.D., (1997). The world wide web: a technology to enhance teaching and learning? American Educational Research Association 26 (2). 27-33.

Polit, D.F., Hungler, B.P. (1993). Essentials of Nursing Research. Philadelphia: J. B. Lippincott Co.

Roy, C., \& Andrews, H.A. (1991). The Roy Adaptation Model: The Definitive Statement. Norwalk, CT: Appleton \& Lange.

Sieber, J., Oneil, H.F., \& Tobias. S. (1977) Anxiety, Learning, and Instruction. New York: Halsted Press. 
Spielberger, C. (1966). Anxiety and Behavior. New York: Academic Press.

Turley, J.P. (1996). Toward a model for nursing informatics. Image Journal of Nursing Scholarship 28 (4) 309-313. 


\section{APPENDICES \\ Consent to Participate in Study}

Test \#

I am surveying graduate nursing students to determine the need for learning experiences in the use of computers and informatics. You do not need to put your name on this form. The tests in your packet are numbered in order to correlate information derived from the computer anxiety survey, and the Informatics needs survey. I assure you that your answers will be held in the strictest confidence. The demographic information will help to interpret the results. These answers will also be confidential. Only aggregated data will be reported: it will not be possible to identify individuals in the reported data. You have a right not to respond to this survey or not to answer specific questions contained in it. There are no known risks associated with the computer anxiety test or the survey of informatics needs. I urge you to complete the questionnaire, since your responses may be used in order to strengthen and enrich nursing informatics education

\section{AGREE FREELY AND VOLUNTARILY TO BE A PARTICIPANT IN THIS} STUDY AND COMPLETION OF THE QUESTIONNAIRES IMPLIES CONSENT. Any questions regarding this study can be answered by Margot Clark RN,BSN principle investigator at:

954-753-7582.

Thank you for your help. 
copyright.

1. Using a hand calculator to add a long list of numbers confident $==\overline{=}=\overline{=}=\underline{=}$ worried

2. Having a hotel or motel bill worked out by a computer distrust $=========== \pm$ trust

3. I generally think of computers as

$$
\text { friendly }==\overline{=}=\overline{=}=\overline{=} \text { unfriendly }
$$

4. Trying to use a small computer to balance a checkbook would usually be frustrating $=\overline{=}=\overline{=}=\overline{=}=\overline{=}$ comfortable

5. Correcting an error on the screen

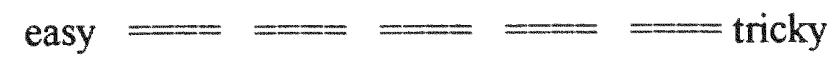

6. Learning to use a small computer to do a budget

$$
\text { comfortable }==\overline{=}===
$$

7. Interpreting a complicated computer printout

$$
\text { worried }==\overline{=}=\overline{=}=\overline{=} \text { secure }
$$

8. Computers give me

$$
\text { more control }=====
$$

9. Making a mistake when entering data for analysis because of nervousness

$$
\text { likely }==\overline{=}=\overline{=}=\overline{=} \text { unlikely }
$$

10. Trying to write a program in BASIC as part of a class

worried $==\overline{=}=\overline{=}$ secure 


\section{ATTITUDES TOWARD COMPUTERS}

\section{DIRECTIONS}

Read each statement and mark the space between the dotted lines to show how you feel about that situation. Look at the following item. If driving in heavy traffic made you feel very nervous, you would make the item like this:

Driving in heavy traffic

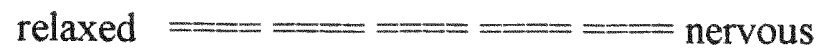

If it made you somewhat nervous, you would mark the item like this:

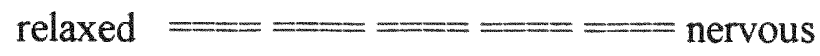

Of course, if you were comfortable driving in heavy traffic you would mark on that side of the scale. If you can't decide, or if you feel midway between the two adjectives, you should mark the middle space.

In the following questions, a "small computer" would be a desk top unit that can be programmed by the operator. It would include a video screen, a keyboard, and possibly a printer. Try to answer every question Some questions may ask about things that you do no know about, or things that you have never actually done. But you can usually figure out what the item means and/or imagine what it would be like to be in that situation. Then mark the item according to how it would make you feel if you were in that situation.

Copyright 1983 by E.R. Oetting, Ph.D. All rights reserved. Published by RMBSI, Inc., P.O. Box 1066, Fort Collins, Colorado 80522. Copies may be made under limited license through Dec. 31, 1984. Copies made after that date will be in violation of the 
11. Deciding which type of personal computer to buy secure $=\overline{=}======\overline{=}=\overline{=}$ insecure

12. Explaining a problem that you have not been able to solve to a computer consultant frightened $=\overline{=}=\overline{=}=\overline{=}$ fearless

13. Using a hand calculator to multiply or divide confident $========$ worried

14. Voting using a computer

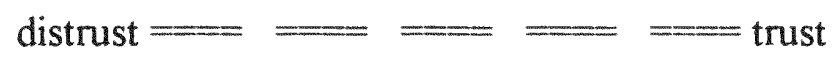

15. Just hearing the word "computer" makes me feel interested $=\overline{=}=\overline{=}=\overline{=}$ nervous

16. Taking a job where you have to regularly enter data into a computer concerned $===\overline{=}=\overline{=}=\overline{=}$ unconcerned

17. Typing on a word processor instead of a typewriter less nervous $\overline{=}=\overline{=}=\overline{=}$ more nervous

18. Learning to keep records for a small business on a computer confident $=\overline{=}=\overline{=}=\overline{=}=\overline{=}$ anxious

19. Knowing the right words or "language" when talking about a computer insecure $==\underline{=}=\overline{=}=$

20. Reading a book about how computers can be used enjoy it $=\overline{=}=\overline{=}=\overline{=}=$

21. Looking at the keyboard of a small computer

$$
\text { anxious }==\overline{=}=\overline{=}=\overline{=}=\overline{c o m f o r t a b l e}
$$


22. Trying to use a small computer to solve math problems

$$
\text { frustrating }====
$$

23. When a message appears on the screen that you have not seen before

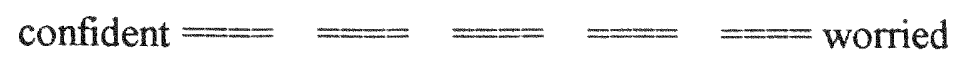

24. Trying to operate a small computer when you are all alone

$$
\text { worried }===\overline{=}=\overline{=}=\overline{=}=\text { unworried }
$$

25. Using a hand calculator to balance a checkbook

$$
\text { relaxed }==\overline{=}=\overline{=}=\overline{=}==\text { nervous }
$$

26. Getting a bank statement printed by a computer

$$
\text { distrust }====
$$

27. Watching computers appear in more and more places

$$
\text { exciting }=\overline{=}=\overline{=}=\overline{=}=\overline{=}=\text { frightening }
$$

28. Learning how to enter long lists of data into a computer

$$
\text { scared }===\overline{=}===\text { comfortable }
$$

29. Typing on a word processor instead of a typewriter

$$
\text { easier }=====
$$

30. Figuring out profits and losses by using a small computer comfortable $===$

31. Discussing computers with a group of people who know a lot about using them insecure $=\overline{=}=\overline{=}=\overline{=}=\overline{\text { safe }}$

32. Learning a new programming language

$$
\text { safe }==\overline{=}==\text { unsafe }
$$


33. When the computer says "INCORRECT ADDRESS"

$$
\text { anxious }==\underline{=}=\underline{=}=\underline{=} \text { confident }
$$

34. Taking a test that requires writing a fairly simple program on a computer

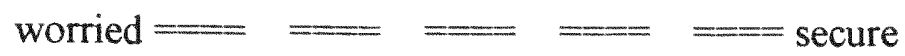

35. Deciding what software to buy for a small computer

$$
\text { confident }==\overline{=}=\overline{=}=\text { = insecure }
$$

36. Consulting a computer manual to find out what you did wrong

$$
\text { anxious }===\overline{=}=\overline{=}=\overline{=} \text { relaxed }
$$

37. Using a hand calculator to calculate a percentage

$$
\text { relaxed }=\overline{=}=\overline{=}=\overline{=}=\text { nervous }
$$

38. Having your vote counted by computer

$$
\text { distrust }===\overline{=}===
$$

39. In general computers are

exciting $=========$

40. Correcting a mistake you made when typing information into a computer concerned $====$

41. Taking a class that requires using a word processor unworried $==\overline{=}====$

42. Using a computer to try out different ideas (What would costs and profits be if comfortable $==\overline{=}=\overline{=}=\overline{=}=\overline{=}$ anxious

43. Taking an advanced course in computer programming

$$
\text { unsafe }=\overline{=}=\overline{=}=\text { safe }
$$


44. Reading a technical book about programming small computers enjoy it $==\overline{=}===\underline{=}==$ avoid it

45. Playing a game on a computer where you have to type in answers to questions

$$
\text { strained }==\overline{=}==\overline{=}===\text { relaxed }
$$

46. Solving simple problems on a small computer with someone nearby to answer questions

$$
\text { anxious }=\overline{=}===\overline{=}=\overline{=}=\overline{c o n f i d e n t}
$$

47. When the keyboard stops working

$$
\text { confident }==\overline{=}===
$$

48. Knowing what to do with a small computer

$$
\text { confused }=====
$$




\section{Survey of Master's Students Concerning}

\section{Computer/Informatics Skills}

By

Felicitas A. Dela Cruz, RN, DNSc

Angeline M. Jacobs, RN, MS

Copyright 1993

1. What is the focus of your master's studies?

1. Adult ARNP

2. Pediatrics ARNP

3. Psych ARNP

4.Other please specify

2. Education background: please check all that apply

LPN

AND

Diploma

BSN

MS

MSN

PHD Other please specify

3. How many semester hours have you completed toward your degree?

4. When do you expect to graduate? (month/year)

5 . What is your age ?

6. How many years of nursing experience do you have?

7. Number of years in clinical positions?

8. Number of years in administrative positions? 
9. Number of years in educational positions?

10. Number of years in other nursing areas? Specify area

11. What is your current position?

Clinical

Education

Administration

Full time student

Other

12. Computers are used:

In my home

At my direct work site

As part of my education

Other

13. I have access to a computer:

At home

At work

At school

Other

14. I am required to use a computer

At home

At work

At school

Other

15. Have you used any of the following systems?

MS-DOS OR PC DOS YES NO

IBM or IBM compatible computer systems Yes

No

Mackintosh computer systems Yes No 
Listed below are some of uses and applications of computers. Please circle in the first column, whether you have ever used a computer in the way indicated by each statement

In the second column, circle the number that reflects the extent of your competence in the stated activity, using the following scale:

$1=$ Beginning knowledge, competence or experience

$2=$ Advanced knowledge, competence or experience

$3=$ Expert knowledge, competence or experience

Activities

16. Word processing

17. Spread Sheets

18. Patient accounts/billing/ Insurance etc.

19. Monitoring patients vital Signs and status

20. Retrieving information about the patient, for example medications, orders, assessment data

21. Obtaining information about Drugs, dosage, side effects

22. Calculations of medication Dosages

23. Planning patient care

24. Documenting patient care

25. Decision analysis

26. Learning modules

27. Statistical analysis
Do you use a computer in this way

Extent of competence
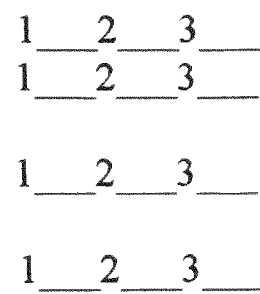

Yes No

Yes No

1

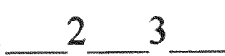

Yes No - No
Yes_No-
Yes_No-
Yes No
Yes No
Yes No N

28. Have you ever personally done a literature search using a computer? Yes

No

29. If yes to question 28 , what software did you use?

30. If you have never actually done a literature search on a computer yourself, have you ever asked anyone to do one for you? Yes No

If your answer to question \#30 was yes: 
31. Who did it?

32. Did you choose the search descriptor word yourself? Yes No

33. If your answer to question $\# 32$ is yes, how competent were you in choosing the descriptors?

I needed a great deal of help from the librarian

I needed help, an will probably need help the next time.

I needed help, but will be able to do it myself the next time.

I did not need help.

34. Which of the following computerized data bases have you had experience using?

Check all that apply

Medline (Medlars on-line)

Health(Health planning and administration)

Cinahl (Cumulative Index to Nursing. \& Allied Health Lit)

ERIC ((Educational Resources Information Center)

Other. Specify

35. Which statement best describes you?

I would like to develop some computer skills to use at:

home

work

school

I would like to advance my computer skills in

Thesis construction

Statistical analysis

Internet

E-mail

Computer fax

Interactive learning modules

Downloading software

Compressing files

Creative presentation construction

Other

Is this the first semester you have attempted to register for nursing informatics class? yes no 
Previous computer education

Undergraduate class

Community college/adult education program

Self-taught

Spouse taught you

Children taught you

Work related training

Other

Stressful computer experiences or general comments:

Thank you for your help. Margot Clark RN.BSN 